Carbohydrate Polymers

Vol. 50, Issue 3 , 15 November 2002, Pages 273-278

http://dx.doi.org/10.1016/S0144-8617(02)00030-9

(c) 2002 Elsevier Science Ltd. All rights reserved
Archimer, archive institutionnelle de l'Ifremer http://www.ifremer.fr/docelec/

\title{
Polysaccharide labelling: impact on structural and biological properties
}

\author{
O. Roger ${ }^{a}$, S. Colliec-Jouault ${ }^{a}$, J. Ratiskol ${ }^{a}$, C. Sinquin ${ }^{a}$, J. Guezennec $^{a}$, A.M. Fischer ${ }^{b}$ and L.
} Chevolot $^{\mathrm{a} *}$

${ }^{a}$ Laboratoire de Biotechnologie et Molécules Marines, Département Valorisation des Produits, VP/BM, IFREMER, rue de l'lle d'Yeu, BP 21105, 44311 Nantes Cedex 3, France.

${ }^{\mathrm{b}}$ Laboratoire d'Hématologie/Hémostase, Faculté des Sciences Pharmaceutiques et Biologiques,

INSERM U 428, 4 avenue de l'Observatoire, 75270 Paris Cedex 06, France.

*: Corresponding author : Lionel.Chevolot@ifremer.fr

\begin{abstract}
:
Three sulphated polysaccharides labelled at the reducing end with three different chemical treatments [2-aminopyridine (2-AP), 8-amino-1,3,6-trisulphonic acid (ANTS) and 6-(biotinyl)-aminocaproylhydrazide $(\mathrm{BACH})]$ were compared. Molecular weight, chemical composition, nuclear magnetic resonance features and anticoagulant activity expressed as activated partial thromboplastin time were studied to determine whether structural and biological properties were retained or not after labelling. Partial depolymerisation and reduced biological activity were observed when reductive amination was performed with 2-AP. The initial properties were better retained with ANTS, and BACH did not modify the anticoagulant and structural properties.
\end{abstract}

Keywords: Sulphated polysaccharide; GAG; Fucan; Fluorescent tagging; Reductive amination; Anticoagulant activity. 


\section{Introduction}

In recent years, there has been increasing interest in the isolation and identification of new bioactive polysaccharides, especially sulphated polysaccharides that occur in a great variety of animals, plants, algae and micro-organisms. These polysaccharides are known for their biological activities resulting from carbohydrate/protein interactions, and heparin-binding proteins play a prominent role in the biology and physiology (Conrad, 1998). In fact, heparin, the best known of these compounds, is widely used for its anticoagulant properties. Nonetheless, some other compounds such as fucoidans have been actively studied as anticoagulant/antithrombotic (Mauray et al., 1995), anti-inflammatory (Blondin et al., 1994), antiviral (Baba et al., 1990), and antiangiogenic (Hahnenberger et al., 1991) agents. Artificially sulphated polysaccharides are already in use, e.g. pentosan polysulphate (Colwell, et al. 1999 ), or are promising candidates, such as bacterial exopolysaccharides (Guezennec et al., 1998). However, methods are needed to facilitate the detection of these low-molecularweight polysaccharides and allow identification, characterisation and studies of their biological functions.

Carbohydrate derivatisation by reductive amination improves sensitivity and facilitates the analysis of this class of compounds. A wide variety of fluorophores have been described, e.g. 2-aminopyridine (2-AP) (Taga et al., 1998) 8-aminonaphthalene-1,3,6-trisulphonic acid (ANTS) (Starr et al., 1994; Che et al., 1999), and some biotinylation reagents such as biotinylated diaminopyridine (Rothenberg et al., 1993). The group of fluorescent tags is useful for purification and analysis of carbohydrates requiring high-performance liquid chromatography or capillary electrophoresis. It is now routinely possible to separate and quantify monosaccharides at the femtomole level (Suzuki et al., 1998). The combination of tags with the reducing end of an oligosaccharide is not a common means of studying biological activities, although it offers some advantages over other reactions involving activation of non-terminal residues, i.e. relatively mild conditions that avoid deep modifications and depolymerisation; no preferential labelling of chains, because there is no specific structural requirement (each chain ends by a terminal reducing sugar); and low risk of modifying the active sequence and inducing a loss of biological activities. Fluorescent tagging by reductive amination is especially promising for studies of protein-sugar interaction by affinity chromatography or electrophoresis.

In our study, three sulphated polysaccharides of various origins were labelled with three different reagents: 2-aminopyridine (2-AP), 8-amino-1,3,6-trisulphonic acid (ANTS), and 6(biotinyl)-aminocaproyl-hydrazide (BACH). The three sulphated polysaccharides were a commercially available heparin, a low-molecular-weight fucan from Ascophyllum nodosum, and a sulphated and partially depolymerised exopolysaccharide (EPS) secreted by a bacterium (Alteromonas infernus) isolated from a hydrothermal deep-sea environment. The chemical characteristics [molecular weight, chemical composition, 1D ${ }^{1} \mathrm{H}$ nuclear magnetic resonance (NMR) spectra] and biological properties (anticoagulant activity) of their derivatives were investigated to determine whether labelled polysaccharides retained the initial properties of free polysaccharides. 


\section{Experimental}

\subsection{Polysaccharides.}

Unfractionated heparin from porcine mucosa [25-35 kDa in low-angle laser measurements by the manufacturer, and $30 \mathrm{kDa}$ as determined in our laboratory (see below)] was from Sigma Chemical (St. Louis, MO, USA). The fucan fraction was obtained from Ascophyllum nodosum and prepared as previously described (Nardella et al., 1996). The isolation procedure and characteristics of the GY785 strain (Alteromonas infernus) were previously reported Raguenes et al.,1997). The exopolysaccharide (EPS) was produced, purified, sulphated and depolymerised according to previously described procedures (Guezennec et al., 1998).

\subsection{Fluorescence labelling.}

2-AP labelling was performed according to Hase et al., (1984), with the following modifications to avoid too large an excess of reagents: reduction of the $\mathrm{NaCNBH}_{3} /$ polysaccharide ratio to 1,000, with a 100-fold excess of 2-AP, and purification of 2-AP-polysaccharides by dialysis against ammonium bicarbonate until no residual UV absorbance was detected at $230 \mathrm{~nm}$ in the baths. A 2-AP solution prepared by dissolving $1 \mathrm{~g}$ of 2-AP (Sigma) in $760 \mu \mathrm{L}$ of hydrochloric acid 37\% (Panreac) could be stored at $-20^{\circ} \mathrm{C}$ for several months. Aqueous sodium cyanoborohydride $\left(\mathrm{NaCNBH}_{3}\right)$ was prepared just before use by dissolving $200 \mathrm{mg}$ of $\mathrm{NaCNBH}_{3}$ (Sigma) in $200 \mu \mathrm{L}$ of distilled water. Fifty milligrams of dry polysaccharide $\left(3.7 \times 10^{-6} \mathrm{~mol}\right)$ were then mixed with $40 \mu \mathrm{L}$ of the 2 -AP solution in a Teflon-lined screw-capped tube and incubated at $65^{\circ} \mathrm{C}$ for $17 \mathrm{~min}$. Two hundred microlitres of the aqueous solution of $\mathrm{NaCNBH}_{3}$ were added, and the preparation was vortex-mixed and heated for $2 \mathrm{~h}$ at $65^{\circ} \mathrm{C}$. After the tube was opened under effective ventilation, the reaction mixture was diluted with $10 \mathrm{~mL}$ of water, dialysed three times against a $50 \mathrm{mM}$ ammonium bicarbonate solution, using a molecular weight cut-off membrane (3,500, Spectra/Por), and finally freeze-dried.

Derivatisation of the polysaccharides with ANTS was performed according to Che et al.(1999). The $\mathrm{NaCNBH}_{3} /$ polysaccharide ratio was 20 with a 10 -fold excess of ANTS (Fluka). Polysaccharides $\left(3.7 \times 10^{-6} \mathrm{~mol}\right)$ were suspended in $300 \mu \mathrm{L}$ of a $0.15 \mathrm{M}$ ANTS solution in $30 \%$ aqueous acetic acid and heated for $15 \mathrm{~min}$ at $45^{\circ} \mathrm{C}$ in a Teflon-lined screw-capped tube. One hundred microlitres of aqueous $\mathrm{NaCNBH}_{3}(0.79 \mathrm{M})$ were added, and the reaction mixture was heated for $25 \mathrm{~h}$ at $40^{\circ} \mathrm{C}$. The reaction was stopped by addition of $10 \mathrm{~mL}$ of water, and the solution was dialysed and freeze-dried as above.

BACH derivatives were prepared according to (Shinohara et al., 1995), with a BACH (Sigma)/polysaccharide ratio of 10 . Fifty milligrams of dry polysaccharides $\left(3.7 \times 10^{-6} \mathrm{~mol}\right)$ were mixed with BACH ( $5 \mathrm{mM}$ in $30 \%$ aqueous acetonitrile). This solution was evaporated to dryness under nitrogen and then dissolved in $1.8 \mathrm{~mL}$ of methanol:water:acetic acid, 95:4:1 $\mathrm{v} / \mathrm{v}$. The reaction mixture was heated for $15 \mathrm{~h}$ at $60^{\circ} \mathrm{C}$ and evaporated to dryness. Ten millilitres of water were added, and the solution was dialysed and freeze-dried as above.

\subsection{Molecular weight determination.}

Molecular weights were determined, as previously described (Nardella et al., 1996), by highperformance steric exclusion chromatography (HPSEC) in $0.1 \mathrm{M}$ ammonium acetate, using a $25 \times 0.4 \mathrm{~cm}$ i.d. Lichrospher $300 \AA$ Diol 7 UM column (Merck S.A., France) and a $25 \times 0.46$ $\mathrm{cm}$ i.d. HEMA SEC BIO $4010 \mathrm{U}$ column (Alltech, France) connected in series. Area measurements and calculations of $\mathrm{Mw}$ (weight-average molecular weight) and I (polydispersity) were performed using ARAMIS software (JMBS Développements, Le Fontanil, France). The columns were calibrated with standard pullulans. As pullulans are neutral glucans and the studied polysaccharides were highly negatively charged, such 
calibration does not allow exact measurement of molecular weight and was only used for relative comparisons.

\subsection{Chemical composition.}

Sulphate content was deduced from sulphur elemental analysis performed for each fraction by the Central Microanalysis Department of the CNRS (Gif sur Yvette, France). The uronic acid content of polysaccharides was determined as previously described (Filisetti-Cozzi and Carpita, 1991). Neutral sugars, after acidic methanolysis of the polymers and subsequent gas chromatography analysis according to Kamerling et al. (1975) and Montreuil et al. (1986), were identified as trimethylsilyl derivatives.

\subsection{NMR spectroscopy.}

1D ${ }^{1} \mathrm{H}$ NMR spectra were recorded on a Bruker $500 \mathrm{MHz}$ at a probe temperature of $298 \mathrm{~K}$. Prior to analysis, samples were exchanged twice in $\mathrm{D}_{2} \mathrm{O}$ with terminate freeze-drying.

\subsection{Tetrazolium blue assay}

The content of reducing ends was determined by addition of 3 volumes of $0.3 \mathrm{M} \mathrm{NaOH}$ to one volume of an aqueous suspension of tetrazolium blue (1\% w/v, Sigma) and diluted 3 times. Nine hundred microlitres of tetrazolium blue solution were added to $100 \mu \mathrm{L}$ of a $5 \mathrm{mg} / \mathrm{mL}$ solution of polysaccharide, and the mixture was heated for $30 \mathrm{sec}$ at $100^{\circ} \mathrm{C}$. The absorbance at $570 \mathrm{~nm}$ was determined after extraction with $1 \mathrm{~mL}$ of toluene (Mullings et al., 1984).

\subsection{Measurement of residual free 2-AP and ANTS}

The high-performance liquid chromatograph consisted of a Merck pump (655A-11) and an SM 4000 UV spectrometer (LDC Analytical). AP-polysaccharides and free AP were separated on a column $\left(4.6 \times 250 \mathrm{~mm}\right.$, LC-318, Supelcosyl ${ }^{\mathrm{TM}}, 300 \AA$, Supelco $)$ using a 0.125 $\mathrm{M}$ citrate buffer $(\mathrm{pH} 4)$ containing $1 \%$ acetonitrile at a flow rate of $1 \mathrm{~mL} / \mathrm{min}$. Free AP and AP derivatives were detected at 228 and $287 \mathrm{~nm}$.

For gel electrophoresis analyses, low-melting-point agarose (1\%) from Biorad was dissolved in the electrophoresis buffer $(50 \mathrm{mM}$ ammonium acetate and $0.5 \%$ 3-[(3cholamidopropyl)dimethylammonio]-1-propanesulphonate (CHAPS) from Sigma, in water). Agarose $(19 \mathrm{~mL})$ was poured hot $\left(>70^{\circ} \mathrm{C}\right)$ on a Gel Bond film (Pharmacia) fitted to a Plexiglas casting tray $(75 \times 100 \mathrm{~mm})$ to obtain a cooled gel $\approx 4 \mathrm{~mm}$ thick. In each $66 \times 1 \mathrm{~mm}$ slot, $20 \mu \mathrm{L}$ of ANTS derivative samples $(10 \mathrm{mg} / \mathrm{mL})$ were mixed with $7 \mu \mathrm{L}$ of a solution containing $480 \mathrm{mg}$ sucrose, $3.2 \mathrm{mg}$ bromophenol blue, and $400 \mu \mathrm{L}$ CHAPS 10\%, completed to $1 \mathrm{~mL}$ with electrophoresis buffer. Electrophoresis was performed at $60 \mathrm{~V}$ with currents at $300 \mathrm{~mA}$ for $3.5 \mathrm{~h}$. Buffer was re-circulated, and a flow of cold water through the coolant ports of the apparatus was used to maintain buffer temperature at $20^{\circ} \mathrm{C}$. After migration, gels were air-dried. For detection of ANTS derivatives, an excitation wavelength of $301 \mathrm{~nm}$ and an emission wavelength of $520 \mathrm{~nm}$ were used on a Fluor-S ${ }^{\mathrm{TM}}$ MultiImager from Biorad.

\subsection{APTT activity.}

Activated partial thromboplastin time (APTT) with the APTT Organon kit (Organon Technika, France) was determined as previously described (Mauray et al., 1995). Free and tagged heparin $(0-5 \mu \mathrm{g} / \mathrm{mL})$, free and tagged fucan fraction $(0-50 \mu \mathrm{g} / \mathrm{mL})$, and free and tagged EPS $(0-30 \mu \mathrm{g} / \mathrm{mL})$ were diluted in human platelet-poor plasma (PPP). These concentrations were chosen to obtain a comparable range of APTT prolongation with all tested products. 


\section{Results and discussion}

All results are given within a 95\% confidence interval based on a minimum of three replications for each fraction.

\subsection{Molecular weight, sulphate content and chemical composition}

The molecular weight and sulphate content of labelled and free polysaccharides are shown in Table 1. In the case of heparin, the three labelling methods induced heparin depolymerisation, increasing its polydispersity and the number of small chains $(<10000$ $\mathrm{g} / \mathrm{mol}$ ). Except for 2-AP labelling, the molecular weight and polydispersity of fucans and EPS derivatives were comparable to those of free fucan and EPS. This lowering of molecular weight was probably due to our experimental conditions (relatively high temperature for 2-AP labelling). Sulphate content (sodium salt) as deduced from sulphur analysis did not change after polysaccharide labelling. Uronic acid content was determined only for heparin and EPS (see Table 2), as fucans possess few uronic acid residues $(<10 \%)$. The amount of uronic acid was the same in heparin and heparin derivatives, as well as in free EPS and EPS derivatives. Neutral sugars were quantified using TMS derivatisation prior to gas chromatography, (Table 3). In both fucan and EPS, the three methods produced no change in the amount of neutral sugars.

\subsection{NMR studies}

No difference was found between labelled and unlabelled products by the above-mentioned methods, which are rather approximate and not accurate enough to detect minor alterations at the biologically important site. However, in NMR studies, the ${ }^{1} \mathrm{H}-1 \mathrm{D}$ NMR spectra of the various derivatives showed previously imperceptible modifications relative to the starting materials. The most obvious difference for 2-AP and ANTS derivatives was the appearance of very small signals corresponding to aromatic protons and due to the labelling groups, which consequently were really linked to the oligosaccharide chain. As there is no well resolved proton in the BACH skeleton, its attachment could not be similarly checked.

Concerning heparin, the main resonances of the osidic chain did not appear to change at first and were consistent with previously published data (Mulloy et al., 1987; Rabenstein et al., 1995; Larnkjaer et al., 1995). Some signals were especially informative because they were characteristic of a kind of residue, e.g. the resonances at 5.23 and $3.3 \mathrm{ppm}$ assigned to $\mathrm{H} 1$ of 2-O-sulphated iduronic acid and $\mathrm{H} 2$ of $\mathrm{N}$-sulphated glucosamine residues, respectively. There was also a sharp peak at $2.06 \mathrm{ppm}$ corresponding to the chemical shift of $\mathrm{CH}_{3}$ on an $\mathrm{N}$ acetylated glucosamine unit (GlcNAc). Using the area of this last signal as a reference (no deacetylation could occur in the conditions used), it was possible to confirm the absence of any modification by measuring the ratio between the area of a distinctive proton and the area of the $2.06 \mathrm{ppm}$ signal. Thus, it was determined that $N$-sulphated D-glucosamine residues were not $\mathrm{N}$-desulphated at all, regardless of the derivative, but that a low percentage of iduronic acid residues was sometimes desulphated at the $O$-2-position.

Concerning fucans, fewer NMR data were available and anomeric protons were poorly resolved, so that quantitative evaluation of modifications was impossible. However, the 5.5 ppm signal present in anticoagulant fucans and assigned to fucose 2,3-O-disulphate units (Chevolot et al., 1999) was less intense after derivatisation, which showed some loss of this important residue (see below). For EPS, no obvious difference was apparent. However, as ${ }^{1} \mathrm{H}-$ 1D NMR spectra of sulphated derivatives are very complex, some undetectable alterations may have occurred. 


\subsection{Yield}

The efficiency of polysaccharide labelling was determined by quantifying the remaining reducing ends by tetrazolium blue assay. After dialysis, no residual free 2-AP or ANTS was detected by gel electrophoresis or HPLC, with a detection limit of $10^{-8}$ and $10^{-12} \mathrm{M}$, respectively (data not shown). The reducing ends labelled with 2-AP or ANTS were estimated to be 90 to $100 \%$ by this method. Measurement was impossible by NMR because the anomeric protons of reducing ends were overlapped by other protons. Concerning BACH derivatives, the amounts of reagent linked to polysaccharides were determined according to Vynios et al., (1999), which indicated that 50 to $60 \%$ of the chains were biotinylated.

\subsection{Anticoagulant activity}

The in vitro anticoagulant activity of labelled and free polysaccharides was evaluated by APTT (Table 4). In the case of heparin, the same anticoagulant effect was obtained for tagged and free heparin: the concentration required to double control time was approximately 1.5 $\mu \mathrm{g} / \mathrm{mL}$ for each product. A very weak activity loss was noted for 2-AP-heparin, probably because of the greater chain shortening observed for this derivative (heparins usually show a lower effect in APTT assay when molecular weight decreases). It was impossible to check the integrity of the antithrombin-binding pentasaccharidic unit by NMR because of signal overlapping. Nevertheless, these results were consistent with NMR data because sulphates borne by glucosamine residues (those important for anticoagulant activity) were not modified (see above). Anticoagulant activities seemed lower with all tagged fucans at both concentrations tested, but particularly at $20 \mu \mathrm{g} / \mathrm{mL}$, although the decrease of molecular mass was no greater than with heparin. This was probably due to alterations of the anticoagulant sequence, as the presence of a few fucose 2,3-O-disulphate residues (as shown by NMR, see above) is important for the anticoagulant activity of fucan (Chevolot et al., 1999). The anticoagulant activity of EPS was roughly not modified by labelling. Otherwise, the concentration doubling control time was approximately $10 \mu \mathrm{g} / \mathrm{mL}$ for free and tagged EPS. 


\section{Conclusion}

In conclusion, labelling the reducing ends of naturally or artificially sulphated polysaccharides with tags (2-AP, ANTS and BACH) had no marked effect on the chemical composition and biological activity of the three polysaccharides. However, molecular size reduction and low desulphation, detectable only by careful examination of NMR spectra, were sometimes observed. These alterations were slightly greater with 2-AP derivatisation and almost totally lacking with BACH, however the labelling yield was relatively low with the latter reagent. Among the three reagents tested, ANTS provided the best compromise for retaining structural integrity and biological activity. Very recently, (Ramsay et al. 2001) proposed novel hydroxylamines as mild tagging reagents. This possibility seems quite promising, but the compounds are not commercially available. Moreover, only oxime was quantitavely formed with a sulphated model compound (GlcNSO3). This is a limitation to the method, because oximes are hydrolysable and form a mixture of various isomers that complicate chromatographic separation. At the present time, there is no "perfect" reagent available, and it is necessary in any case to test and select the most convenient reagent for each kind of oligosaccharide. The present study indicates that ANTS as a labelling reagent induces few alterations. In addition, this reagent provides three negative charges, thereby facilitating the study of neutral oligosaccharides by electrophoresis or electrospray mass spectrometry. Thus, this sensitive technique could be a very useful tool for the discovery and characterisation of new bioactive sulphated polysaccharides.

\section{Acknowledgements:}

The authors are grateful to Drs J. Jozefonvicz and P. Durand for their attention to this work and to Mr J. Gray for reviewing and improving the original text. They are especially indebted to N. Kervarec for recording NMR spectra. This work was supported by the CNRS and IFREMER. 


\section{References}

Baba, M., Schols, D., Pauwels, R., Nakashima, H. and De Clercq, E. (1990). Sulfated polysaccharides as potent inhibitors of HIV-induced syncytium formation: a new strategy towards AIDS chemotherapy. J. Acquir. Immune. Defic. Syndr., 3, 493-9.

Blondin, C., Fischer, AM., Boisson-Vidal, C., Kazatchkine, M.D. and Jozefonvicz, J. (1994). Inhibition of complement activation by natural sulfated polysaccharides (fucans) from brown seaweed. Mol. Immunol., 31, 247-53.

Che, F., Song, J., Zeng, R., Wang, K. and Xia, Q. (1999). Analysis of 8-aminonaphthalene1,3,6-trisulfonate-derivatized oligosaccharides by capillary electrophoresis-electrospray ionization quadrupole ion trap mass spectrometry. J. Chromatogr. A., 858, 229-238.

Chevolot, L., Foucault, A., Chaubet, F., Kervarec, N., Sinquin, C., Fisher, A.M. and BoissonVidal, C. (1999). Further data on the structure of brown seaweed fucans: relationships with anticoagulant activity. Carbohydr. Res., 319, 154-65.

Conrad, H.E. (1998). Heparin-binding protein in hemostasis. Heparin-binding protein (pp. 239-301). Academic Press.

Colwell, N. S. Grupe, M. J. Tollefsen, D. M. (1999). Amino acid residues of heparin cofactor II required for stimulation of thrombin inhibition by sulphated polyanions. Biochim. Biophys. Acta., 1431, 148-156.

Filisetti-Cozzi, T.M. and Carpita, N.C. (1991). Measurement of uronic acids without interference from neutral sugars. Anal. Biochem., 197, 157-62.

Guezennec, J., Pignet, P., Lijour, Y., Gentric, E., Ratiskol, J. and Colliec-Jouault, S. (1998). Sulfation and depolymerization of a bacterial exopolysaccharide of hydrothermal origin. Carbohydr. Polym. 37, 19-24.

Hahnenberger, R. and Jakobson, A.M. (1991). Antiangiogenic effect of sulphated and nonsulphated glycosaminoglycans and polysaccharides in the chick embryo chorioallantoic membrane. Glycoconj. J., 8, 350-3.

Hase, S., Ibuki, T. and Ikenaka, T. (1984). Reexamination of the pyridylamination used for fluorescence labeling of oligosaccharides and its application to glycoproteins. J. Biochem. (Tokyo), 95, 197-203.

Kamerling, J.P., Gerwig, G.J., Vliegenthart, J.F. and Clamp, J.R. (1975). Characterization by gas-liquid chromatography-mass spectrometry and proton-magnetic-resonance spectroscopy of pertrimethylsilyl methyl glycosides obtained in the methanolysis of glycoproteins and glycopeptides. Biochem. J., 151, 491-5.

Larnkjaer, A., Hansen, S. H., Ostergaard, P. B. (1995). Isolation and characterization of hexasaccharides derived from heparin. Analysis by HPLC and elucidation of structure by $1 \mathrm{H}$ NMR. Carbohydr. Res., 266, 37-52.

Mauray, S., Sternberg, C., Theveniaux, J., Millet, J., Sinquin, C., Tapon Bretaudiere, J. and 
Fischer, A.M. (1995). Venous antithrombotic and anticoagulant activities of a fucoidan fraction. Thromb. Haemostasis, 74, 1280-1285.

Montreuil, J., Bouquelet, S., Debray, H., Fournet, B., Spik, G. and Strecker, G. (1986). Glycoproteins. In M.F. Chaplin and J.K. Kennedy (Eds), Carbohydrate analysis: A practical approch, (pp. 143-204), Oxford: IRL Press.

Mullings, R. and Parish, J.H. (1984). New reducing sugar assay for the study of cellulases. Enzyme Microb. Technol., 6, 491-496.

Mulloy, B. and Johnson, E.A. (1987). Assignment of the 1H-n.m.r. spectra of heparin and heparan sulphate. Carbohydr. Res., 170, 151-65.

Nardella, A., Chaubet, F., Boisson-Vidal, C., Blondin, C., Durand, P. and Jozefonvicz, J. (1996). Anticoagulant low molecular weight fucans produced by radical process and ion exchange chromatography of high molecular weight fucans extracted from the brown seaweed Ascophyllum nodosum. Carbohydr. Res., 289, 201-8.

Rabenstein, D.L., Robert, J.M. and Peng J. (1995). Multinuclear magnetic resonance studies of the interaction of inorganic cations with heparin. Carbohydr. Res., 278, 239-56.

Raguenes, G. H., Peres, A., Ruimy, R., Pignet, P., Christen, R., Loaec, M., Rougeaux, H., Barbier, G., Guezennec, J. (1997). Alteromonas infernus sp. nov., a new polysaccharideproducing bacterium isolated from a deep-sea hydrothermal vent. J. Appl. Microbiol., 82, 422-30.

Ramsay, S. L., Freeman, C., Grace, P. B., Redmond, J. W. MacLeod, J. K. (2001). Mild tagging procedures for the structural analysis of glycans. Carbohydr. Res., 333, 59-71.

Rothenberg, E., Hayes, K., Toomre, D., Manzi, E. and Varki, A. (1993). Biotinylated diaminopyridine: An approche to tagging oligosaccharides and exploring their biology. proc. nat. acad., 90, 11939-11943.

Shinohara, Y., Sota, H., Kim, F., Shimizu, M., Gotoh, M., Tosu, M. and Hasegawa, Y. (1995). Use of a biosensor based on surface plasmon resonance and biotinyl glycans for analysis of sugar binding specificities of lectines. J. Biochem. (Tokyo), 117, 1076-1082.

Starr, C., Klock, J., Skop, E., Masada, I. and Guidici, T. (1994). Fluorophore-assised electrophoresis of urinary carbohydrates for the identification of patients with oligosaccharidosis- and mucopolysaccharidosis-type lysosomal storage diseases. Glycosilation and disease, 1, 165-176.

Suzuki, S. and Honda, S. (1998). A tabulated review of capillary electrophoresis of carbohydrates. Electrophoresis, 19, 2539-60.

Taga, A., Yabusako, Y., Kitano, A. and Honda, S. (1998). Separation of disaccharides by affinity capillary electrophoresis in lectin-containing electrophoretic solutions. Electrophoresis, 19, 2645-9.

Vynios, D.H., Faraos, A., Spyracopoulou, G., Aletras, A.J. and Tsiganos, C.P. (1999). A 
solid-phase assay for quantitative analysis of sulfated glycosaminoglycans at the nanogram level. Application to tissue samples. J. Pharm. Biomed. Anal., 21, 859-65. 
Table 1

Molecular mass and sulfur content of labelled and unlabelled low molecular weight polysaccharides

\begin{tabular}{lccccc}
\hline & Mp g/mol & $\mathrm{I}^{\mathrm{a}}$ & $\mathrm{Mw} \mathrm{g}^{\mathrm{a}} \mathrm{mol}^{\mathrm{a}}$ & ${\mathrm{Mn} \mathrm{g} / \mathrm{mol}^{\mathrm{a}}}$ & $\mathrm{S}(\%)^{\mathrm{b}}$ \\
\hline Heparin & & & & & \\
2-AP-Heparin & 29800 & 1.82 & 30400 & 16800 & 9.3 \\
ANTS-Heparin & 15500 & 2.7 & 13100 & 4800 & 9.7 \\
BACH-Heparin & 21700 & 2.6 & 18500 & 6900 & 9.0 \\
& 25200 & 2.8 & 25300 & 8800 & 9.3 \\
& & & & & \\
LMW-Fucan & 26900 & 2.3 & 23600 & 10200 & 11.0 \\
2-AP LMW-Fucan & 16700 & 2.2 & 14500 & 6700 & 10.8 \\
ANTS-LMW- & 26600 & 2.5 & 24700 & 9400 & 10.0 \\
Fucan & & & & & \\
BACH-LMW- & 25100 & 2.4 & 22800 & 9400 & 11.0 \\
Fucan & & & & & \\
& & & & & \\
\hline & & & & & \\
LMW-EPS & 35800 & 1.7 & 37500 & 21200 & 13.0 \\
2-AP-LMW-EPS & 9100 & 1.0 & 9500 & 9400 & 11.5 \\
ANTS-LMW-EPS & 27800 & 1.8 & 30600 & 17100 & 12.0 \\
BACH-LMW-EPS & 38600 & 1.8 & 41000 & 22700 & 13.0 \\
& & & & & \\
\hline
\end{tabular}

${ }^{\text {a }} \mathrm{Mp}$ (peak-molecular weight), Mn (number-average molecular weight), Mw (weightedaverage molecular weight) and I (polydispersity) were measured by HPSEC using pullulans as standards.

${ }^{\mathrm{b}}$ Performed using elemental analysis 
Table 2

Uronic acid content of labelled and unlabelled heparin and EPS.

\begin{tabular}{lc}
\hline & $\begin{array}{c}\text { Uronic acids } \\
(\%)\end{array}$ \\
\hline & 52.2 \\
Heparin & 53.6 \\
2-AP-Heparin & 61.5 \\
ANTS-Heparin & 64.9 \\
BACH-Heparin & \\
\hline & \\
LMW-EPS & 24.1 \\
2-AP-LMW-EPS & 23.0 \\
ANTS-LMW-EPS & 26.5 \\
BACH-LMW-EPS & 25.0 \\
& \\
\hline
\end{tabular}

Uronic acid content was determined according to the procedure described by Filisetti-Cozzi and Carpita (1991). 


\section{Table 3}

Neutral sugars composition of labelled and unlabelled low molecular weight polysaccharides.

\begin{tabular}{lcccc}
\hline Composition & Fucose (\%) & $\begin{array}{c}\text { Galactose } \\
(\%)\end{array}$ & Xylose (\%) & total (\%) \\
\hline LMW-Fucan & 33.0 & 1.5 & 1.6 & 36.1 \\
2-AP-LMW-Fucan & 44.7 & 1.3 & 1.9 & 47.9 \\
ANTS-LMW-Fucan & 58.2 & 1.8 & 3.0 & 63.0 \\
BACH-LMW-Fucan & 43.0 & $<1$ & $<1$ & 43.0 \\
\hline
\end{tabular}

\begin{tabular}{lccccccc}
\hline Composition & Rham (\%) & A Glu (\%) & A Gal (\%) & man (\%) & Gal (\%) & Glu (\%) & total (\%) \\
\hline \multirow{2}{*}{ LMW-EPS } & 1.9 & 3.7 & 4.4 & 2.2 & 12.1 & 14.3 & 38.6 \\
2-AP-LMW-EPS & 5.0 & 4.4 & 5.0 & 3.8 & 10.2 & 13.0 & 41.4 \\
ANTS-LMW-EPS & 2.2 & 2.5 & 1.8 & 1.6 & 8.8 & 12.0 & 27.3 \\
BACH-LMW-EPS & 2.8 & 2.5 & 2.6 & 2.6 & 10.8 & 13.9 & 35.2 .5 \\
\hline
\end{tabular}

Neutral sugars composition was performed by G.C. analysis using trimethylsilyl derivatives after acidic methanolysis 
Table 4

Anticoagulant activity measured by activated partial thromboplastin time performed with the Organon APTT kit

Activated partial thromboplastin time (seconds)

$0 \mu \mathrm{g} / \mathrm{mL} \quad 1.5 \mu \mathrm{g} / \mathrm{mL} \quad 3 \mu \mathrm{g} / \mathrm{mL}$

Heparin

$36.8 \pm 1.0 \quad 85.0 \pm 2 \quad 178.0 \pm 5$

2-AP-Heparin

$39.0 \pm 1.6 \quad 75.0 \pm 1.5 \quad 112.3 \pm 4.1$

ANTS-Heparin

$38.7 \pm 1.1 \quad 86.9 \pm 2.0 \quad 148.0 \pm 4.2$

BACH-Heparin

$38.9 \pm 1.1 \quad 85.0 \pm 2.4 \quad 137.2 \pm 3.2$

$0 \mu \mathrm{g} / \mathrm{mL} \quad 20 \mu \mathrm{g} / \mathrm{mL} \quad 40 \mu \mathrm{g} / \mathrm{mL}$

$\begin{array}{lccc}\text { Fucan } & 40.1 \pm 0.5 & 78.4 \pm 5.8 & 117.0 \pm 4 \\ \text { 2-AP-Fucan } & 38.9 \pm 1.1 & 56.6 \pm 1.5 & 103.0 \pm 1.3 \\ \text { ANTS-Fucan } & 38.7 \pm 1.0 & 54.9 \pm 3.2 & 92.3 \pm 4.0 \\ \text { BACH-Fucan } & 38.9 \pm 1.1 & 47.5 \pm 0.5 & 110.1 \pm 0.6\end{array}$

$0 \mu \mathrm{g} / \mathrm{mL} \quad 10 \mu \mathrm{g} / \mathrm{mL} \quad 20 \mu \mathrm{g} / \mathrm{mL}$

$\begin{array}{lll}\text { LMW-EPS } \quad 39.0 \pm 1.6 & 85.0 \pm 2 & 121.1 \pm 2\end{array}$

2-AP-LMW-EPS $\quad 37.6 \pm 0.9 \quad 72.2 \pm 1.4 \quad 107.2 \pm 2.6$

ANTS-LMW-EPS $\quad 38.7 \pm 1.1 \quad 87.0 \pm 1.4 \quad 110.1 \pm 4.4$

BACH-LMW-EPS $\quad 39.0 \pm 1.6 \quad 83.9 \pm 0.6 \quad 143.7 \pm 1.6$

Results are expressed as means \pm S.D. $(n=3$ or 4$)$ 